\title{
Analisis Faktor yang Memengaruhi Keberhasilan Kehamilan pada Inseminasi Intrauterin
}

\author{
Angghea Rachmiawaty, Tono Djuwantono, R. M. Sonny Sasotya \\ Departemen Obstetri dan Ginekologi Fakultas Kedokteran Universitas Padjadjaran \\ Rumah Sakit Dr. Hasan Sadikin Bandung \\ Korespondensi: Angghea Rachmiawati,Email: a.rachmiawaty@gmail.com
}

\begin{abstract}
Abstrak
Tujuan: Inseminasi intrauterin (IIU) merupakan prosedur yang umum digunakan dan menjadi pilihan terapi pertama dalam tatalaksana infertilitas, karena dampak risiko yang rendah, implementasi yang mudah, dan harga yang murah.

Metode: Penelitian cross-sectional ini dilakukan pada seluruh pasangan yang melakukan prosedur IIU di Poliklinik Aster Rumah Sakit dr. Hasan Sadikin Bandung pada periode 1 Januari 2016 sampai dengan 31 Desember 2016, yang tercatat dalam rekam medik. Variabel penelitian berupa Umur Istri, Umur Suami, Jumlah Sperma, Konsentrasi Sperma, dan Motilitas Sperma, Ketebalan Endometrium, Jumlah Folikel preovulasi, Jenis Stimulasi dan Output. Data dikelola dengan SPSS 24.00. Hasilnya disajikan secara analitik melalui angka dan tabel.

Hasil: Diantara 159 pasangan yang melakukan prosedur IIU, terdapat 194 prosedur. Namun hanya 98 subjek yang dapat dievaluasi. Angka kehamilan sebesar 23.5\%. Faktor yang mempengaruhi hanya jenis stimulasi ovarium dan jumlah ovum preovulasi yang berhubungan secara signifikan dengan angka kehamilan $(\mathrm{p}<0,05)$, umur pasangan, jumlah, konsentrasi, dan motilitas sperma tidak berbeda bermakna.

Kesimpulan: Berbagai variabel mempengaruhi keberhasilan dari IIU. Jenis stimulasi ovarium dan jumlah ovum preovulasi berhubungan secara signifikan dengan angka kehamilan $(\mathrm{p}<0,05)$.
\end{abstract}

Kata kunci: Inseminasi intrauterin, infertilitas, stimulasi ovarium

\section{Factors Analizyng of Influencing for Succeses Pregnancy Rate on Intrauterina Insemination}

\begin{abstract}
Objective: intrauterine insemination (IUI) is a procedure widely used in fertility management. However, the effectiveness of IUI treatment is not consistent, and the role of multiple factor affecting successes in IUI has not been clarified.

Methods: Cross sectional study was conducted on infertile couples performing IUI. Data from medical record at Aster Clinique Dr. Hasan Sadikin General Hospital at January 1st-December 12th, 2016. Spouse Ages, Sperm Count, Concentration, and Motility, Endometrial Thickness, Number of Preovulatory Follicles, Type of Stimulation and Output are research variables. Data was analyzed by SPSS 24.00.

Results: Among 159 couples, there were 194 procedures of IUI. Only 98 subject was evaluated. The pregnancy rate was $23.5 \%$. Only type of ovarian stimulation and number of preovulatory follicle related significantly to the pregnancy rate $(p<0.05)$, spouse age, sperm count, concentration and motility, endometrial thickness did not significantly related to the pregnancy rate $(p>0,05)$

Conclusion: There were many variables may influence success rates of IUI. Type of ovarian stimulation and number of preovulatory follicle related significantly to the pregnancy rate $(p<0.05)$. More cohort trials and randomized trials investigating the multiple factors affecting successes in IUI are urgently needed.
\end{abstract}

Keywords: Intrauterine insemination, infertility, ovarian stimulation 


\section{Pendahuluan}

Infertilitas merupakan kegagalan pasangan untuk mendapatkan atau mempertahankan kehamilan sekurang-kurangnya dalam 12 bulan berhubungan seksual secara teratur tanpa menggunakan pengaman. ${ }^{1-3}$ Penyebab infertilitas dapat berasal dari faktor perempuan, laki-laki maupun keduanya, namun infertilitas idiopatik juga dapat terjadi ketika pasangan infertil telah menjalani pemeriksaan standar meliputi tes ovulasi, patensi tuba, dan analisis semen dengan hasil normal. ${ }^{4}$

Infertilitas merupakan permasalahan yang banyak ditemukan pada pasangan produktif. Pada tahun 2010, diperkirakan 48.5 juta pasangan didunia infertil dengan prevalensi tertinggi di Asia Tenggara. ${ }^{5}$ Di Indonesia, 40 juta pasangan mengalami masa subur, $10-15 \%$ diantaranya mengalami infertilitas dan gangguan kesuburan. ${ }^{6} \mathrm{Di}$ Jawa Barat diperkirakan sekitar 10-15\% dari jumlah penduduk mengalami infertilitas. ${ }^{7}$ Penyebab infertilitas sebesar $20-40 \%$ disebabkan disfungsi ovulasi, dan sebesar 30 - $40 \%$ akibat faktor laki-laki. ${ }^{8}$

Penanganan infertilitas berdasarkan pada hasil evaluasi terhadap penyebab infertilitas, lama pasangan mengalami kondisi infertil, usia, kondisi kesehatan umum dan pilihan kedua pasangan. Terapi yang dapat ditawarkan berupa Teknologi Reproduksi Berbantu (assisted reproductive technology, ART), berupa inseminasi intrauterin (IIU), fertilisasi in vitro, fertilisasi in vitro dengan injeksi sperma intra sitoplasmik (ICSI), penggunaan donor sperma atau donor sel telur, dan pemindahan embrio. ${ }^{9}$

Inseminasi intra uterin (IIU) merupakan suatu prosedur teknologi reproduksi berbantu untuk mengatasi masalah infertilitas. Tujuan prosedur IIU dilakukan untuk mengurangi faktor yang menghalangi fungsi sperma, misalnya keasaman vagina dan pengaruh lendir serviks yang tidak menguntungkan.
Angka kehamilan IIU berkisar antara $8-12 \%$ persiklus. ${ }^{10-12}$ Dilakukan dengan cara memasukan dan menempatkan sperma yang sudah dipersiapkan dan diproses sebelumnya kedalam uterus pada saat diperkirakan terjadi ovulasi. Sperma yang dimasukan memiliki konsentrasi, motilitas dan morfologi tertentu. ${ }^{10}$ Telah diketahui bahwa berbagai faktor terlibat pada angka kehamilan dari prosedur IIU, namun masih banyak perdebatan mengenai hubungannya terhadap keberhasilan IIU. ${ }^{13}$

Berdasarkan hal tersebut, pendidikan untuk mengetahui faktor-faktor yang memengaruhi keberhasilan IIU merupakan hal yang perlu diteliti.

\section{Metode}

Penelitian ini merupakan penelitian crosssectional. Data diambil dari data rekam medik yang tercatat di klinik Aster RS dr.Hasan Sadikin Bandung pada tahun 2016. Penelitian dilakukan pada bulan Februari Mei 2017, di Poliklinik Aster RS dr.Hasan Sadikin Bandung. Subyek pada penelitian ini adalah seluruh pasangan yang melakukan prosedur IIU di klinik Aster Rumah Sakit Dr. Hasan Sadikin Bandung pada periode 1 Januari 2016 sampai dengan 31 Desember 2016, yang tercatat dalam rekam medik.

Kriteria eklusi dari penelitian ini berupa endometriosis, kelainan uterus dan tuba, infertilitas pada pria derjat berat dengan spermatozoa yang kuantitasnya kurang, data tercatat tidak lengkap dalam rekam medik.

Berdasarkan rekam medik tersebut, dilakukan evaluasi kelengkapan data yang diperlukan. Data yang diteliti dimasukan dalam database dan diolah dengan program SPSS 24.00. Data yang didapatkan dimasukan dalam sebuah tabel induk, kemudian ditabulasi.

Analisis pada data numerik ini diuji dengan menggunakan uji T tidak berpasangan apabila data berdistribusi normal serta 
alternatif uji Mann Whitney apabila data tidak berdistribusi normal, uji Chi Squre atau Exact Fisher. Hasil uji statistik dapat diperoleh informasi nilai $\mathrm{p}$, yang berarti signifikan nilai $\mathrm{p}<0,05$ dianggap bukan secara statistik.

\section{Hasil}

Penelitian ini melibatkan 159 pasangan, dengan 194 prosedur IIU, hanya 98 subjek yang dapat dievaluasi berdasarkan kriteria inklusi. Pada penelitian ini didapatkan angka kehamilan 23.5\%. Adapun karakteristik berbagai faktor yang mempengaruhi keberhasilan kehamilan pada inseminasi intrauterin dapat dijelaskan pada tabel 1

Tabel 1 menjelaskan karakteristik subjek dari keseluruhan pasien penelitian menurut umur istri, umur suami, jumlah sperma, konsentrasi sperma, dan motilitas sperma, ketebalan endometrium, jumlah folikel preovulasi, jenis stimulasi dan output. Data selanjutnya dikelompokan berdasarkan output IIU. Pada penelitian ini, didapatkan rerata umur istri sebesar 32.1 (3.7), dan umur suami sebesar 35.7 (5.4) pada kelompok hamil. Pada pria kelompok hamil didapatkan rata-rata jumlah sperma yang diinseminasi sebesar 7.7 (11.4) dengan rata rata konsentrasi sebesar 31.56 \pm 46.547 , dan ratarata motilitas sperma sebesar 81.7 (7.5). Pada wanita kelompok hamil didapatkan tebal endometrium memiliki rata-rata sebesar 8.8 (1.9), untuk rata-rata jumlah folikel rata-rata sebesar 3.2 (2.0). Karakteristik dari jenis stimulasi, didapatkan jenis Gonadotropin $39.7 \%$, kemudian diikuti dengan AI sebesar $21.7 \%$.
Tabel 1 Karakteristik Subjek Penelitian

\begin{tabular}{lc}
\hline \multicolumn{1}{c}{ Variabel } & N=98 \\
\hline Umur Istri (Tahun) & \\
Rerata (simpang baku) & $33.08(4.8)$ \\
Umur Suami (Tahun) & \\
Rerata (simpang Baku) & $36.76(6.7)$ \\
Jumlah Sperma (Juta) & \\
Rerata (simpang Baku) & $5.64(8.1)$ \\
Konsentrasi (Juta/ml) & \\
Rerata (simpang Baku) & $24.04(33.2)$ \\
Motilitas (\%) & \\
Rerata (simpang Baku) & \\
Ketebal Endometrium (mm) & $75.23(18.9)$ \\
Rerata (simpang baku) & \\
Jumlah Folikel Preovulasi & $8.34 \pm 2.030$ \\
Rerata (simpang baku) & \\
Jenis Stimulasi & $3.00(3.3)$ \\
AI & \\
CC & $35(35.7 \%)$ \\
Gonadotropin & $9(9.2 \%)$ \\
Kombinasi (CC+FSH) & $19(19.4 \%)$ \\
Kombinasi (FSH+AI) & $6(6.1 \%)$ \\
Natural Cycle & $3(3.1 \%)$ \\
Output & $26(26.5 \%)$ \\
Tidak Hamil & \\
\hline & \\
\hline
\end{tabular}

Keterangan : Untuk data kategorik disajikan dengan jumlah/ frekuensi dan persentase sedangkan data numerik disajikan dengan rerata, median, standar deviasi dan range 
Tabel 2 Perbandingan antara Umur istri, Umur suami, Jumlah sperma yang di inseminasi, Konsentrasi post washing, Motilitas dan Tebal Endometrium pada Kelompok Hamil dan Kelompok Tidak Hamil.

\begin{tabular}{lccc}
\hline \multicolumn{1}{c}{ Variabel } & \multicolumn{2}{c}{ Kelompok } & \\
\cline { 2 - 3 } & $\begin{array}{c}\text { Hamil } \\
\mathbf{N = 2 3}\end{array}$ & $\begin{array}{c}\text { Tidak Hamil } \\
\text { N=75 }\end{array}$ & Nilai P \\
\hline $\begin{array}{l}\text { Umur Istri } \\
\text { Rerata (simpang baku) }\end{array}$ & $32.13(3.8)$ & $33.37(5.1)$ & $\mathbf{0 . 3 5 2}$ \\
$\begin{array}{l}\text { Umur Suami } \\
\text { Rerata (simpang baku) }\end{array}$ & $35.73(5.5)$ & $37.08(7)$ & $\mathbf{0 . 6 2 0}$ \\
$\begin{array}{l}\text { Jumlah Sperma (Juta) } \\
\text { Rerata (simpang baku) }\end{array}$ & $7.78(11.4)$ & $4.98(7)$ & $\mathbf{0 . 8 1 0}$ \\
$\begin{array}{l}\text { Konsentrasi } \\
\text { Rerata (simpang baku) } \\
\text { Motilitas (\%) }\end{array}$ & $31.56(46.6)$ & $21.74(27.9)$ & $\mathbf{0 . 1 2 6}$ \\
$\begin{array}{l}\text { Rerata (simpang baku) } \\
\text { Tebal Endometrium } \\
\text { Rerata (simpang baku) }\end{array}$ & $81.73(7.6)$ & $73.24(21)$ & $\mathbf{0 . 0 9 7}$ \\
\hline
\end{tabular}

Keterangan : Tanda* menunjukkan nilai $\mathrm{p}<0,05$ artinya signifkan atau bermakna secara statistik.

Tabel 3 Perbandingan antara Jumlah Folikel Preovulasi dan Jenis Stimulasi pada Kelompok Hamil dan Kelompok Tidak Hamil.

\begin{tabular}{|c|c|c|c|}
\hline \multirow{3}{*}{ Variabel } & \multicolumn{2}{|c|}{ Kelompok } & \multirow{3}{*}{ Nilai $P$} \\
\hline & Hamil & $\begin{array}{r}\text { Tidak } \\
\text { Hamil }\end{array}$ & \\
\hline & $\mathbf{N}=\mathbf{2 3}$ & $\mathrm{N}=75$ & \\
\hline Jumlah Folikel & & & $0.033 * *$ \\
\hline \multicolumn{4}{|l|}{ Preovulasi } \\
\hline $\operatorname{Mean} \pm \operatorname{Std}$ & $3.21 \pm 2.021$ & $2.93 \pm 3.618$ & \\
\hline Range (min-max) & $1.00-10.00$ & $0.00-18.00$ & \\
\hline
\end{tabular}

Keterangan : Tanda* menunjukkan nilai $\mathrm{p}<0,05$ artinya signifkan atau bermakna secara statistik.

\section{Pembahasan}

Pada penelitian ini didapatkan angka kehamilan sebesar 23.5\%, dengan melibatkan 98 subjek yang dapat dievaluasi berdasarkan kriteria inklusi. Pada studi lain, angka kehamilan IIU berkisar antara 8-12\% persiklus. ${ }^{10}$ Telah diketahui bahwa berbagai faktor terlibat pada angka kehamilan dari prosedur IIU. Penelitian ini menyajikan hubungan berbagai faktor terhadap keberhasilan IIU, berupa usia pasangan, jenis stimulasi, jumlah, konsentrasi, dan motilitas sperma sebagai faktor pria, jumlah folikel dan tebal endometrium sebagai faktor wanita.

Terdapat banyak penelitian mengenai hubungan bermakna antara faktor usia wanita terhadap angka kehamilan, ${ }^{14,15}$ meskipun 
demikian pada penelitian ini tidak menunjukan hubungan signifikan, hal ini mungkin disebabkan rerata umur pada kelompok wanita hamil dan tidak hamil tidak terlalu berbeda. Sejumlah penelitian juga mengungkapkan faktor sperma, seperti jumlah, konsentrasi, dan motilitas sperma, pada angka-angka tertentu berhubungan terhadap kesuksesan IIU, ${ }^{16-19}$ namun pada penelitian ini tidak didapatkan hubungan yang signifikan. Tebal endometrium merupakan salah satu faktor wanita yang diduga menjadi berhubungan dengan keberhasilan IIU, ${ }^{12,20,21}$ namun pada penelitian ini tidak menunjukan hubungan yang bermakna.

Terdapat perbedaan bentuk atau jumlah polikel preovulasi dengan jenis simulasi atau kelompok yang hamil dengan tidak hamil. Hubungan bermakna terhadap kehamilan dari prosedur IIU yang dilakukan. Telah diketahui jumlah Folikel Preovulasi dan jenis stimulasi ovarium merupakan faktor wanita yang dapat mempengaruhi angka kehamilan. Pada penelitian ini, wanita kelompok hamil didapatkan rata-rata jumlah folikel rata-rata sebesar $3.21 \pm 2.021$ dan kehamilan banyak ditemukan pada jenis stimulasi Gonadotropin $(39.7 \%)$.

Stimulasi ovum bertujuan untuk mengembangkan folikel lebih dari satu. ${ }^{16}$ Pada penelitian ini, jenis stimulasi memiliki hubungan bermakna terhadap angka kehamilan. Sejalan dengan Aboulghar dkk dan Liu dkk yang telah melaporkan angka kehamilan lebih tinggi secara signifikan pada prosedur IIU yang disertai stimulasi ovarium. $^{22,23}$ Jenis stimulasi yang paling banyak dilakukan dari seluruh subjek penelitian berupa AI yaitu sebesar 35\%, sebanyak $38.7 \%$ kehamilan pada kelompok wanita hamil, IIU dilakukan disertai dengan jenis stimulasi Gonadotropin. Meskipun CC menjadi pilihan pertama dari jenis stimulasi ovarium, ${ }^{16}$ namun pada penelitian ini hanya $4.3 \%$ wanita hamil yang hamil dengan menggunakan CC. Gomez et al, telah melaporkan bahwa $\mathrm{CC}$ memiliki angka kehamilan lebih kecil dibandingkan dengan Gonadotropin dan AI. ${ }^{11}$ Penelitian lain yang dikemukan Cantineau etal menyatakan bahwa stimulasi ovarium dengan gonadotropin berhubungan secara bermakna pada angka kehamilan yang tinggi. ${ }^{24}$ Pada prinsipnya gonadotropin memanipulasi jendela FSH sehingga didapatkan paparan yang lebih lama terhadap kohort folikel, proses pematangan menjadi lebih panjang, dan folikel yang matang menjadi lebih banyak.

Penelitian yang dilakukan Iberico et al dan Dickey dkk menunjukan kesuksesan prosedur IIU banyak terdapat pada jumlah folikel preovulasi dominan sebanyak dua sampai tiga folikel. ${ }^{17}$ Yavuz dkk juga melaporkan bahwa angka kehamilan pada IIU 8 kali meningkat jika ditemukan folikel dominan lebih dari tiga folikel. ${ }^{18}$ Pematangan folikel secara multipel meningkatkan fertilitas dari oosit dan kualitas endometrium pada fase luteal yang berhubungan dengan kesuksesan fertilisasi dan implantasi. Kualitas folikel juga dapat dinilai dengan melihat diameter dari folikel, ${ }^{20}$ namun karena keterbatasan data diameter folikel tidak diikutsertakan pada penelitian ini.

Diperlukan penelitian lebih lanjut dan seksama mengenai peran berbagai faktor yang mempengaruhi angka kehamilan IIU. Selain itu diperlukan penelitian lanjutan secara mendalam mengenai output dari IIU. Simpulan dari penelitian ini adalah: angka kehamilan pada penelitian lebih tinggi dari literatur yang ada, jenis stimulasi dan dan jumlah folikel preovulasi berhubungan signifikan terhadap angka kehamilan, sedangkan usia pasangan, profil sperma berupa jumlah, konsentrasi, dan motilitas, dan tebal endometrium tidak berhubungan secara signika terhadap angka kehamilan. Perlunya penelitian lebih lanjut mengenai peran berbagai faktor dari IIU, pada penelitian ini belum melibatkan faktor sosial ekonomi. 


\section{Daftar Pustaka}

1. Konsensus penanganan infertilitas edisi Himpunan Fertilitas dan Endokrinologi Reproduksi, Perhimpunan Fertilitas In Vitro Indonesia, HERDFI, PFIVI, IAUI, (POGI) POdGI, penyunting. Jakarta; 2013.

2. Aubuchon M, Burney RO, Schust DJ, Yao MWM. Infertility and Assisted Reproductive Technology. Dalam: Berek JS, penyunting. Berek and Novak's. Edisi. Philadelphia: Lippincott williams and wilkins, a Wolters Kluwer Business; 2012.

3. Zegers-Hochschild F, Adamson GD, de Mouzon J, Ishihara $\mathrm{O}$, Mansour $\mathrm{R}$, Nygren $\mathrm{K}$, et al. The international committee for monitoring assisted reproductive technology (ICMART) and the world health organization (WHO) revised glossary on ART terminology, 2009. Hum Reprod. 2009;24(11):2683-7.

4. Hestiantoro A, Natadisastra M, Sumapraja $\mathrm{K}$, Wiweko B. Bagaimana menangani kasus endokrinologi dan infertilitas pada praktik sehari-hari. edisi Jakarta: Badan Penerbit Fakultas Kedokteran Universitas Indonesia; 2014.

5. Mascarenhas MN, Flaxman SR, Boerma T, Vanderpoel S, Stevens GA. National, regional, and global trends in infertility prevalence since 1990: a systematic analysis of 277 health surveys. PLoS Med. 2012;9(12):e1001356.

6. Wahyuni T. Empat Juta Pasangan Indonesia Punya Masalah Kesuburan. Journal [serial on the Internet]. 2015 Date: Available from: http:// w w w. c n nindonesia.com/g a y a hidup/20151223033551-255-99982/ empat-juta-pasangan-indonesia-punyamasalah kesuburan/.

7. Djuwantono T, Ritonga MNA. Teknik Anamnesis Pasien Infertilitas; Berbasis Pengalaman Empiris dan Evidence Based
Medicine. Dalam: Astarto NW, Permadi W, Djuwantono T, Aji HB, penyunting. Infertilitas Dasar. Edisi. Bandung: Himpunan Endokrinologi Reproduksi dan Fertilitas Indonesia Cabang Bandung; 2010. hlm. 1-25.

8. Fritz MA, SperoffL. Clinical Gynecologic Endocrinology and Infertility. Edisi ke8. Philadelphia: Lippincott Williams \& Wilkins; 2011.

9. Irawati S. Terapi farmakologi infertilitas pada wanita. Rasional. 2012;10(2).

10. Samsulhadi, Hendarto H. Induksi ovualsi dan stimulasi ovarium. Edisi. Jakarta: CV Sagung Seto; 2009.

11. Gomez R, Schorsch M, Steetskamp J, Hahn T, Heidner K, Seufert R, et al. The effect of ovarian stimulation on the outcome of intrauterine insemination. Arch of Gynecol \& Obstet. 2014;289(1).

12. MervielP, Heraud MH, Grenier N, Lourdel E, Sanguinet P, Copin H. Predictive factors for pregnancy after intrauterine insemination (IUI): an analysis of 1038 cycles and a review of the literature. Fertil Steril. 2010;93(1):79-88.

13. Aubuchon M, Burney RO, Schust DJ, Yao MWM. Infertility and assisted reproductive technology. Dalam: Berek JS, penyunting. Berek and Novak's Gynecology. Edisi ke-5. Philadephia: Lippincott Williams and Wilkins; 2012.

14. No CO. Female age-related fertility decline. Fertil Steril. 2014;101(3):633-4.

15. Hansen KR, He ALW, Styer AK, Wild RA, Butts S, Engmann L, et al. Predictors of pregnancy and live-birth in couples with unexplained infertility after ovarian stimulation-intrauterine insemination. Fertil Steril. 2016;105(6):1575-83. e2.

16. Ombelet W. Evidence-based recommendations for IUI in daily practice. Middle East Fertil Soc J. 2013;18(2):747.

17. Ibérico G, Vioque J, Ariza N, Lozano JM, Roca M, Llácer J, et al. Analysis of 
factors influencing pregnancy rates in homologous intrauterine insemination. Fertil Steril. 2004;81(5):1308-13.

18. Yavuz A, Demirci O, Sözen H, Uludoğan M. Predictive factors influencing pregnancy rates after intrauterine insemination. Int $\mathrm{J}$ Reprod Biomed. 2013;11(3):227.

19. Nikbakht R, Saharkhiz N. The influence of sperm morphology, total motile sperm count of semen and the number of motile sperm inseminated in sperm samples on the success of intrauterine insemination. Int J Fertil Steril. 2011;5(3):168.

20. Nargund G, Sarafis V, Campbell S. Factors influencing IUI outcome: perifollicular flow and endometrial thickness. Dalam: Cohlen B, Ombelet W, penyunting. IntraUterine Insemination Evidence-Based Guidelines for Daily Practice. edisi. New York: CRC Press; 2014. hlm. 61-6.
21. Esmailzadeh S, Faramarzi M. Endometrial thickness and pregnancy outcome after intrauterine insemination. Fertil Steril. 2007;88(2):432-7.

22. Liu J, Chian R, Ma X, Wang W, Cui Y. The pregnancy outcomes comparison on natural or controlled ovarian stimulation cycles in intrauterine insemination treatment: an analysis of 8,893 cycles. La Prensa Medica. 2016;2016.

23. Aboulghar M, Baird D, Collins J, Evers JL, Fauser BC, Lambalk C, et al. Intrauterine insemination. Hum Reprod Update. 2009;15(3):265-77.

24. Cantineau A, Cohlen B, Heineman M. Ovarian stimulation protocols (antioestrogens, gonadotrophins with and without GnRH agonists/antagonists) for intrauterine insemination (IUI) in women with subfertility. Cochrane Database Syst Rev. 2005;2. 